\title{
Neogene radiolarian biostratigraphy and faunal evolution rates in the eastern equatorial Pacific ODP Sites 845 and 1241
}

Shin-Ichi Kamikuri, Isao Motoyama, Hiroshi Nishi, and Masao Iwai Acta Palaeontologica Polonica 54 (4), 2009: 713-742 doi: http://dx.doi.org/10.4202/app.2008.0076

Radiolarians from Sites 845 and 1241 in the eastern equatorial Pacific were examined in order to evaluate the role of paleoceanographic perturbations upon the general faunal evolutionary pattern of tropical planktonic organisms during the last $17 \mathrm{Ma}$. Radiolarian appearance and extinction rates indicate no periods of mass extinctions during the past $17 \mathrm{Ma}$. However, a relatively rapid replacement of the species in the radiolarian assemblages occurs near the middle-late Miocene boundary. This replacement event represents the gradual extinction of a number of radiolarian species and their gradual replacement by evolving new species. The modern equatorial circulation system was formed near the middle-late Miocene boundary due to the closure of the Indonesian seaway. The minor faunal turnover appears to be associated with the formation of the modern equatorial circulation system near the middle-late Miocene boundary. Diatom assemblages in the equatorial Pacific became more provincial in character after about 9 Ma. The appearance and extinction rates of planktic foraminifers were relatively high near the middle-late Miocene boundary, and those of calcareous nannoplankton reached high values in the early late Miocene in the equatorial Pacific Ocean. Thus, faunal evolution from the middle Miocene type to late Miocene types occurred first, being followed by floral evolution. The middle-late Miocene boundary is not a sharp boundary for planktonic microfossils, but marks a time of transition critical for faunal and floral evolution in both siliceous and calcareous microfossil assemblages in the equatorial Pacific Ocean.

Key words: Radiolaria, biostratigraphy, faunal evolution, middle-late Miocene boundary, eastern equatorial Pacific.

Shin-ichi Kamikuri [kamikuri@geol.tsukuba.ac.jp] and Isao Motoyama [isaomoto@sakura.cc.tsukuba.ac.jp], Department of Earth Evolution Sciences, University of Tsukuba, Tsukuba 305-8572, Japan; Hiroshi Nishi [hnishi@mail.sci.hokudai.ac.jp], The Graduate School of Science, Hokkaido University, Sapporo 060-0810, Japan; Masao Iwai [iwaim@kochi-u.ac.jp], Department of Natural Science, Kochi University, Kochi 780-8520, Japan. 
This is an open-access article distributed under the terms of the Creative Commons

Attribution License (for details please see creativecommons.org), which permits unrestricted use, distribution, and reproduction in any medium, provided the original author and source are credited.

Forif Full text $(2,593.7 \mathrm{kB})$ 